\title{
Effect of light-curing method and indirect veneering materials on the Knoop hardness of a resin cement
}

\section{Nelson Tetsu Iriyama(a) (in memoriam) \\ Rubens Nisie Tango ${ }^{(b)}$ \\ Izabella Paola Manetta(a) \\ Mário Alexandre Coelho \\ Sinhoreti(c) \\ Lourenço Correr Sobrinho(c) \\ Guilherme de Siqueira Ferreira \\ Anzaloni Saavedra ${ }^{(d)}$}

(a)DDS; (c) Head Professor, Department of Restorative Dentistry - Piracicaba Dental School, University of Campinas (UNICAMP), Campinas, SP, Brazil.

(b) Professor, Department of Dental Materials and Prosthodontics, School of Dentistry of São José dos Campos, São Paulo State University (UNESP), São José dos Campos, SP, Brazil.

(d) PhD Student, Department of Restorative Dentistry, School of Dentistry of São José dos Campos, São Paulo State University (UNESP), São José dos Campos, SP, Brazil.

\begin{abstract}
This study evaluated the Knoop hardness of a dual-cured resin cement (Rely-X ARC) activated solely by chemical reaction (control group) or by chemical / physical mode, light-cured through a $1.5 \mathrm{~mm}$ thick ceramic (HeraCeram) or composite (Artglass) disc. Light curing was carried out using conventional halogen light (XL2500) for $40 \mathrm{~s}$ (QTH); light emitting diodes (Ultrablue Is) for $40 \mathrm{~s}$ (LED); and Xenon plasma arc (Apollo 95E) for $3 \mathrm{~s} \mathrm{(PAC).} \mathrm{Bovine} \mathrm{incisors} \mathrm{had} \mathrm{their} \mathrm{buc-}$ cal face flattened and hybridized. On this surface a rubber mold $(5 \mathrm{~mm}$ in diameter and $1 \mathrm{~mm}$ in height) was bulk filled with the resin cement. A polyester strip was seated for direct light curing or through the discs of veneering materials. After dry storage in the dark $\left(24 \mathrm{~h} / 37^{\circ} \mathrm{C}\right)$, the samples $(\mathrm{n}=5)$ were sectioned for hardness $(\mathrm{KHN})$ measurements, taken in a microhardness tester $(50 \mathrm{gF}$ load/15 s). The data were statistically analyzed by ANOVA and Tukey's test $(\alpha=0.05)$. The cement presented higher Knoop hardness values with Artglass for QTH and LED, compared to HeraCeram. The control group and the PAC/Artglass group showed lower hardness values compared to the groups light-cured with QTH and LED. PAC/HeraCeram resulted in the worst combination for cement hardness values.
\end{abstract}

Descriptors: Resin cements; Hardness; Composite resins; Dental porcelain.

\footnotetext{
Corresponding author:

Rubens Nisie Tango

Área de Materiais Dentários, Departamento de Materiais Odontológicos e Prótese,

Faculdade de Odontologia de São José dos Campos, UNESP

Av. Eng. Francisco José Longo, 777

São José do Campos - SP - Brazil

CEP: 12245-000

E-mail: tango@fosjc.unesp.br
}

Received for publication on Mar 29, 2007

Accepted for publication on Sep 20, 2007 


\section{Introduction}

The use of resin cements has grown in the last few years due to an increased application of esthetic indirect restorative materials such as ceramics and resin composites. As advantages, these cements present adhesion to substrates due to compatibility with silane agents and adhesive systems, low solubility, easy handling properties and favourable aesthetics when used with metal-free ceramic systems. The application of these cements can still result in higher fatigue compressive strength of all-ceramic crowns compared to glass ionomer cements and to zinc phosphate cements. ${ }^{1}$

In spite of the variety of available cements, there is no ideal cement for all clinical situations. Therefore, the choice of the luting agent must rely on its physical, biological and manipulation properties added to the characteristics of the remainder of the prepared tooth and the prosthesis. ${ }^{2}$

The final quality of the restoration can be influenced by factors such as light-curing method and exposure time, type of indirect restorative material and also by the luting agent. ${ }^{3-5}$ Inlays, onlays, laminate veneers and all-ceramic crowns are commonly luted with dual-cured resin cements because light transmission through the indirect restorative is reduced, so the chemical reaction should theoretically guarantee a satisfactory degree of conversion. It has been observed that the light transmission spectrum through ceramic is influenced by its thickness, shade, and opacity. ${ }^{6,7}$ The influence of these factors can also be observed during the cementation of laminate veneers made of indirect resin composite. ${ }^{3}$ The application of longer light-curing times results in higher resin composite polymerization depth, higher degree of conversion and higher hardness values, ${ }^{3,7}$ and, consequently, in improved mechanical and aesthetic properties. ${ }^{8}$ According to Tanoue et al..$^{9}$ (2001), the same can be applied to light-cured resin cements.

The hardness test is commonly used as a simple and reliable method to indirectly indicate the degree of conversion of resin cements. ${ }^{10}$ The degree of conversion in a polymerization reaction depends on the energy supplied during light curing, characterized as the product of the light intensity and expo- sure time. ${ }^{11}$ Dual-cured resin cements present higher hardness values compared to cements that are lightcured solely, ${ }^{3}$ and light-activated dual-cured resin cements present higher hardness values compared to dual-cured resin cements polymerised chemically. ${ }^{11}$ Witzel et al. ${ }^{12}$ (2003) demonstrated that dual-cured resin cements, when not light-cured and associated to one-bottle adhesive systems, resulted in lower bond strength values compared to those obtained with light-cured dual activated cements.

Light curing is usually performed with Quartz Tungsten Halogen light-curing units. Other recent light-curing technologies such as Xenon plasma arc (PAC) and light emitting diodes (LED) are also available. Their application is growing fast in spite of the ongoing development of these systems. Doubts about the effectiveness of light-activation of resin cements with different methods using these light-curing units still exist. The null hypotheses tested were: (1) there is no difference in the degree of cure of the resin cement promoted by different curing units; (2) there is no difference in the degree of cure obtained by means of light activation through different veneering materials and (3) the light activation mode does not influence the microhardness values of the resin cement.

\section{Material and Methods}

For this study a disc-shaped specimen $(1.5 \mathrm{~mm}$ in thickness and $7 \mathrm{~mm}$ in diameter) was prepared for each veneering material: a feldspathic ceramic (HeraCeram, Heraeus Kulzer, Wehrhein, Germany) and an indirect resin composite (Artglass, Heraeus Kulzer, Wehrhein, Germany).

In order to simulate the cementation procedures, a bovine incisor was sectioned and its coronal portion was embedded in polystyrene resin maintaining the buccal surface exposed. This surface was ground flat under water-cooling with \#200, 400 and 600 grit SiC sandpapers (Saint-Gobain, Recife, PE, Brazil), to obtain a dentine area of at least $25 \mathrm{~mm}^{2}$. On this surface a polyester strip was seated, and over this set a rubber mould $(5 \mathrm{~mm}$ in diameter and $1 \mathrm{~mm}$ in height) was bulk filled with resin cement. The dual-cured resin cement Rely-X ARC (3M ESPE, Saint Paul, MN, USA), shade A3, was manip- 
ulated according to the manufacturer's instructions. A polyester strip was seated over this set, and with a disc of veneering material the cement was digitally compressed for excess flow and removal. Light curing was carried out with a conventional quartz tungsten halogen (QTH) light-curing unit (LCU) (XL 2500, 3M ESPE, Saint Paul, MN, USA) for $40 \mathrm{~s}$ at $700 \mathrm{~mW} / \mathrm{cm}^{2}$, light emitting diodes (LED) (Ultrablue Is, DMC Equip. Ltda., São Carlos, SP, Brazil) for $40 \mathrm{~s}$ at $440 \mathrm{~mW} / \mathrm{cm}^{2}$, and with a Xenon plasma arc (PAC) (Apollo 95E, DMD Equip. Ltd., Westlake Village, CA, USA) for $3 \mathrm{~s}$ at $1,600 \mathrm{~mW} / \mathrm{cm}^{2}$. As control group, the cement was set to cure by chemical reaction only.

After light curing, the specimens $(\mathrm{n}=5)$ were stored dry in the dark at $37^{\circ} \mathrm{C}$, for $24 \mathrm{~h}$. To perform resin cement Knoop hardness measurements, the samples were embedded in self-cured acrylic resin, and sectioned longitudinally under water-cooling with a diamond saw (Extec model 12205, Extec corp., Enfield, CT, USA). The surface obtained by sectioning was polished sequentially under watercooling with SiC sandpapers with \# 400, 600 and 1,200 grit.

Indentations and micro-hardness measurements (KHN) were performed sequentially, in a microhardness tester machine (HMV-2000, Shimadzu, Tokyo, Japan). Three indentations were performed in each depth of 100, 500 and $900 \mu \mathrm{m}$ from the top surface, with load of $50 \mathrm{gf}$ for $15 \mathrm{~s}$.

For each specimen, a mean hardness value was obtained from nine measurements, and the data were submitted to one-way ANOVA and to Tukey's test at the $5 \%$ level of significance.

\section{Results}

ANOVA showed statistically significant differences among the groups $(\mathrm{p}<0.05)$. Tukey's test showed that the resin cement presented higher Knoop hardness values with Artglass for QTH and LED, compared to HeraCeram. The control group and the PAC/Artglass group showed lower hardness values compared to the groups light-cured with QTH and LED. PAC/HeraCeram resulted in the worst combination for cement hardness values (Table 1).

\section{Discussion}

According to the results (Table 1), the null hypotheses of this study were rejected. The results (Table 1) showed that lower hardness values were obtained when the resin cement Rely-X was light-cured with PAC compared to QTH and LED. Light curing with QTH and LED resulted in similar hardness values. This behaviour might be due to the short exposure time during light-curing with $\mathrm{PAC},,^{13,14}$ that resulted in a low energy density supplied to the resin cement. This lower energy leads to a lower degree of conversion of the cement, which is determined indirectly by hardness values measurements. ${ }^{15}$ It can be hypothesised that with an increase in light-curing exposure time, hardness values similar to those produced by QTH and LED would be obtained. The results of this study are in agreement with those of Rasetto et al..$^{5}$ (2001). On the other hand, Ozyesil et al. ${ }^{16}$ (2004) observed similar degrees of conversion for the resin cement Variolink II light-cured with conventional QTH and PAC.

The veneering material also influenced resin cement hardness. Higher hardness values were observed with Artglass compared to HeraCeram (Table 1). This might be the result of the different nature of these materials, which entails distinct optical characteristics. It was not possible to compare these results with those reported in the literature because studies using this methodology were not found. Light curing with PAC through HeraCeram resulted in the lowest hardness values, even when compared

Table 1 - Comparison of the Knoop hardness values (KHN) (SD) of the resin cement polymerized under different conditions.

\begin{tabular}{c|c}
\hline Treatment & KHN (SD) \\
\hline QTH/Artglass & $51.76(5.01) \mathrm{a}$ \\
\hline LED/Artglass & $51.50(4.11) \mathrm{a}$ \\
\hline QTH/HeraCeram & $45.35(6.04) \mathrm{b}$ \\
\hline LED/ HeraCeram & $44.47(4.90) \mathrm{b}$ \\
\hline Chemical & $28.47(2.99) \mathrm{c}$ \\
\hline PAC/Artglass & $26.26(4.93) \mathrm{c}$ \\
\hline PAC/HeraCeram & $21.82(3.81) \mathrm{d}$ \\
\hline
\end{tabular}

Means followed by different letters are significantly different by the Tukey test $(p<0.05)$. 
to those of solely chemical-cured cement (Table 1). It could be supposed that the light scattering and refracting determined by HeraCeram would be higher compared to that of Artglass. The lower values observed for PAC could be the result of the light attenuation produced by the veneering materials, and by the resin cement per se. ${ }^{17}$ Another hypothesis was that light curing with PAC through HeraCeram induced an initiation of the polymerization reaction characterised by cross-linking formation. It could have reduced monomer mobility in the mass bulk, thus decreasing polymerization complementation by the chemical-cure ${ }^{18}$ According to Soh, Yap, ${ }^{18}$ in 2004, light curing with high intensity would lead to a highly cross-linked polymer chain, and to higher hardness. In regions submitted to low energy density, the polymer chain would be more linear with higher mobility, and lower hardness values.

Cementation using dual-cured resin cements has been indicated due to the presence of chemical initiators that would, theoretically, guarantee a reliable

\section{References}

1. Groten M, Probster L. The influence of different cementation modes on the fracture resistance of feldspathic ceramic crowns. Int J Prosthodont. 1997;10(2):169-77.

2. Rosenstiel SF, Land MF, Crispin BJ. Dental luting agents: a review of the current literature. J Prosthet Dent. 1998;80(3):280301.

3. Breeding LC, Dixon DL, Caughman WF. The curing potential of light-activated composite resin luting agents. J Prosthet Dent. 1991;65(4):512-8.

4. Rahiotis C, Kakaboura A, Loukidis M, Vougiouklakis G. Curing efficiency of various types of light-curing units. Eur J Oral Sci. 2004;112(1):89-94.

5. Rasetto FH, Driscoll CF, von Fraunhofer JA. Effect of light source and time on the polymerization of resin cement through ceramic veneers. J Prosthodont. 2001;10(3):133-9.

6. O'Keefe KL, Pease PL, Herrin HK. Variables affecting the spectral transmittance of light through porcelain veneer samples. J Prosthet Dent. 1991;66(4):434-8.

7. Uctasli S, Hasanreisoglu U, Wilson HJ. The attenuation of radiation by porcelain and its effect on polymerization of resin cements. J Oral Rehabil. 1994;21(5):565-75.

8. Watts DC, Cash AJ. Analysis of optical transmission by 400$500 \mathrm{~nm}$ visible light into aesthetic dental biomaterials. J Dent. 1994;22(2):112-7. cement polymerization even with a deficient lightcuring. ${ }^{19}$ Peutzfeldt ${ }^{20}$ (1995) observed that the best mechanical properties of the dual-cured cements were obtained with light curing, avoiding the polymerization reaction by chemical curing alone.

Further studies are necessary on the veneering materials' characteristics, and on the search for reasonable light-curing exposure times with PAC for dual-cured cement polymerization.

\section{Conclusions}

Based on the results obtained in the present investigation, it could be concluded that:

1. Higher hardness values were obtained with QTH and LED, compared to PAC and the chemicalcured group.

2. Light curing through Artglass resulted in higher hardness values compared to HeraCeram.

3. Light curing with PAC for just $3 \mathrm{~s}$ negatively influenced resin cement hardness.

9. Tanoue N, Koishi Y, Matsumura H, Atsuta M. Curing depth of different shades of a photo-activated prosthetic composite material. J Oral Rehabil. 2001;28(7):618-23.

10. Darr AH, Jacobsen PH. Conversion of dual cure luting cements. J Oral Rehabil. 1995;22(1):43-7.

11. Rueggeberg FA, Caughman WF, Curtis JW Jr. Effect of light intensity and exposure duration on cure of resin composite. Oper Dent. 1994;19(1):26-32.

12. Witzel MF, Braga RR, Singer JM, Azevedo CL. Bond strength between polymer resin-based cement and porcelain-dentin surfaces: influence of polymerization mode and early cyclic loading. Int J Prosthodont. 2003;16(2):145-9.

13. Deb S, Sehmi H. A comparative study of the properties of dental resin composites polymerized with plasma and halogen light. Dent Mater. 2003;19(6):517-22.

14. Jung H, Friedl KH, Hiller KA, Haller A, Schmalz G. Curing efficiency of different polymerization methods through ceramic restorations. Clin Oral Investig. 2001;5(3):156-61.

15. Sharkey S, Ray N, Burke F, Ziada H, Hannigan A. Surface hardness of light-activated resin composites cured by two different visible-light sources: an in vitro study. Quintessence Int. 2001;32:401-5.

16. Ozyesil AG, Usumez A, Gunduz B. The efficiency of different light sources to polymerize composite beneath a simulated ceramic restoration. J Prosthet Dent. 2004;91(2):151-7. 
Effect of light-curing method and indirect veneering materials on the Knoop hardness of a resin cement

17. Knezevic A, Tarle Z, Meniga A, Sutalo J, Pichler G, Ristic M. Photopolymerization of composite resins with plasma light. J Oral Rehabil. 2002;29(8):782-6.

18. Soh MS, Yap AU. Influence of curing modes on crosslink density in polymer structures. J Dent. 2004;32(4):321-6.
19. Kramer N, Lohbauer U, Frankenberger R. Adhesive luting of indirect restorations. Am J Dent. 2000;13(Spec No):60D76D.

20. Peutzfeldt A. Dual-cure resin cements: in vitro wear and effect of quantity of remaining double bonds, filler volume, and light curing. Acta Odontol Scand. 1995;53(1):29-34. 